\title{
KONSEP FANTASI DALAM FILM
}

\author{
Danissa Dyah Oktaviani \\ Program Studi Komunikasi Penyiaran Islam, Fakultas Dakwah dan Komunikasi Islam \\ Institut Agama Islam Negeri Kudus \\ Jalan Conge Ngembalrejo No. 51, Ngembalrejo, Bae, Kudus, Jawa Tengah 59322 \\ Jurusan Produksi Film dan Program Televisi \\ SMK Negeri 6 Surakarta \\ Jalan Adi Sucipto No. 38, Kerten, Laweyan, Kota Surakarta, Jawa Tengah 57143 \\ No.Hp.: 08192007100,E-mail: danissado@gmail.com
}

\begin{abstract}
ABSTRAK
Film fantasi lahir dari pengembangan film fiksi yang sudah menunjukkan eksistensi sejak awal sejarahnya. Film fantasi memiliki daya tarik tersendiri karena dapat menembus ruang dan waktu dibandingkan dengan genre yang lain. Film fiksi berkembang dari kreatornya baik dari segi cerita maupun sinematografinya karena film fiksi berada di tengah-tengah kutub: nyata dan abstrak. Kekuatan terbesarnya terdapat pada kemampuan memadukan dan mengombinasi genre-genre yang lain tanpa terkecuali serta dapat dikembangkan secara luas tidak terbatas. Hal tersebut dikarenakan film fantasi memuat unsur-unsur dengan karakteristik yang berbeda dari film-film, yang jika memiliki satu unsur dalam pembuatan filmnya, sebuah film sudah dikatakan sebagai film fantasi. Unsur atau komponen yang dilihat berasal dari unsur naratif dan sinematik pembuatan film yang di dalamnya memuat ide cerita, karakter, dan latar dalam sebuah film. Ketiga unsur tersebut adalah komponen pembentuk film fantasi yang bersifat fiktif dan imajinatif. Ide ceritanya tidak berdasarkan kenyataan yang bersifat imajiner, yaitu karangan fiksi yang tidak masuk akal. Dalam kasus film fantasi, pembuat film akan berlomba mengembangkan dan menghadirkan ide-ide yang belum terpikirkan sebelumnya sehingga penonton seakan-akan terbawa dalam dunia baru di luar kehidupan nyata. Karakter tokoh dalam film fantasi merupakan hasil imajinasi kreatornya dalam wujud yang fiktif, seperti karakter binatang, makhluk luar angkasa, monster, robot, dan karakter nonfisik seperti hantu, arwah, dan hologram. Unsur latar dalam film fantasi mempunyai karakter latar tempat, sedangkan waktu kejadian imajinatif mempunyai keunikan pada zaman atau dimensi yang tidak diketahui, dapat berupa masa lalu, masa sekarang, dan masa depan dengan peradaban yang dibentuk oleh kreatornya.
\end{abstract}

Kata kunci: fantasi, fiktif, imajinatif

\section{ABSTRACT}

Fantasy Concepts on Film. Fantasy films were born from the development of fiction films that have shown existence since the beginning of its history. Fantasy films have their own charm because they can penetrate time and space compared to other genres. Fiction films have been developed from their creators both in terms of story and cinematography because fiction films are at the center of the poles: real and abstract. Its greatest strength lies in its ability to integrate and combine with other genres without exception and can be broadly developed unlimitedly. That is because fantasy films contain elements with different characteristics from other films, if a fantasy film has one element in the making of the film then it has been said to be a fantasy film. The elements or components that are seen derived from the narrative and cinematic elements of filmmaking which contain ideas of stories, characters, and settings in a film. These three elements are the forming components of fantasy films that are fictitious and imaginative. The idea of the story is not based on an imaginary reality, that a fiction makes 
no sense. In the case of fantasy films, filmmakers will strive to develop and present ideas that have not been thought of before, so the audience seems to be carried away in a new world outside of real life. The characterization of characters in fantasy films are the imagination of creators in fictitious forms, such as: animal characters, extraterrestrials, monsters, robots, and non-physical characters such as ghosts, spirits, and holograms. The background elements in fantasy films have a character of setting, while the imaginative events are unique in their unknown times or dimensions, which can be past, present, and future with the civilization formed by the creators.

Keywords: fantasy, fictitious, imaginative

\section{PENDAHULUAN}

Seni film merupakan cabang kesenian berusia muda yang terlaris dengan segala keunikannya. Perkembangan film dari waktu ke waktu semakin mendapat respons positif dari khalayak. Seni film lahir karena adanya kebutuhan untuk menyatakan sesuatu yang berbetuk seni (Ismail, 1986). Film berkembang secara sistematis dan tradisional sesuai dengan ilmu pengetahuan yang menyertainya. Pergerakan globalisasi telah berhasil membangun suatu sistem informasi yang mampu memengaruhi perkembangan budaya, ilmu pengetahuan, dan teknologi (Luthfi, 2017). Selain semakin banyaknya layar bioskop yang bermunculan dibarengi dengan peningkatan kualitas yang semakin mumpuni dan memiliki tingkat daya saing yang ketat, salah satu indikator adanya perkembangan tersebut dapat dilihat dari banyaknya genre film yang semakin berkembang. Perkembangan genre diperoleh dari kreativitas filmmaker yang bisa mengolah ide menjadi film-film bergenre baru atau mengembangkan satu genre tertentu dengan ide-ide baru sehingga menghasilkan sensasi menonton yang berbeda. Film fantasi merupakan salah satu genre film yang memberikan ruang yang luas bagi filmmaker untuk mengembangkan kreativitas. Hal tersebut dikarenakan film fantasi dapat menembus dimensi ruang dan waktu tidak terbatas.
Dalam perkembangannya film fantasi sudah memiliki penggemarnya tersendiri karena dapat menghadirkan sensasi-sensasi menonton film yang berbeda yang tidak bisa ditemui dalam dunia nyata. Metode penelitian yang digunakan adalah analisis genre yang di dalamnya memuat enam unsur, yaitu setting, lokasi, ikonografi, peristiwa-peristiwa naratif, karakter-karakter, dan struktur plot (Stokes, 2007).

Fantasi adalah imajinasi atau khayalan mengenai sesuatu yang benar-benar tidak ada dan tidak terjadi berdasarkan pengalaman yang sudah ada atau pernah dialami. Fantasi dalam film merujuk pada sifat film, yaitu bagaimana pembuat film berimajinasi menciptakan dunia baru di luar nalar manusia dan bukan bagaimana tokoh berfantasi dalam cerita. Fantasi dalam film akan mengerucut pada penyebutan dengan label "film fantasi". Film fantasi merujuk pada film yang berhubungan dengan unsur magis, mitos, negeri dongeng, imajinasi, halusinasi, serta alam mimpi yang di dalamnya memuat pedang sakti, mantera gaib, naga, raksasa, kuda terbang, karpet terbang, dewa-dewi, penyihir, jin, serta peri adalah yang sering kali muncul dalam film fantasi (Pratista, 2017). Dalam dua dekade belakangan ini, film fantasi semakin menunjukkan eksistensinya dengan menduduki film-film box office terbaik di dunia. Keberhasilan film fantasi dibuktikan dengan dibuatnya film-film sekuel, seri, dan remake. 
Hal tersebut menunjukkan antusias khalayak yang tinggi terhadap keberadaan film fantasi.

Salah satu tokoh yang menjadi cikal bakal berkembangnya film fantasi adalah Georges Milies, yang memperlakukan film bukan sekadar rekaman keseharian kreatornya. Lewat Le Voyage dans la Lune atau A Trip to the Moon (1902), Melise memperlakukan film dengan pendekatan yang lebih kreatif, yang memanfaatkan film untuk mengungkapkan dongeng fantasik, antara lain lewat teknik efek spesial dan tipuan sulap dalam menciptakan gambar-gambar khayal. Karena hasil kreativitasnya tersebut, Georges Milies disebut sebagai bapak film cerita (Suwardi, 2006). Film fantasi menyusup dalam tayangan film di seluruh lapisan usia dari anak-anak hingga dewasa. Film fantasi yang disuguhkan untuk kalangan semua umur, di antaranya adalah Doraemon, The Jungle Book, Minions, Frozen, Tangled, dan Moana. Studio Disney adalah salah satu yang mengembangkan film bergenre film animasi fantasi. Bahkan kini Disney melakukan produksi ulang atau remake untuk film-film sukses garapan sebelumnya menjadi film live-action, seperti The Junggle Book, Cinderella, Maleficent, Pete's Dragon, dan Beauty and The Beast. Selain itu, jenis film fantasi mengagumkan yang membuat sekuel dan spint off hingga lima film atau lebih seperti Harry Potter dan Beast and Where to Find Them, kemudian film The Lord of the Ring sukses dengan pengembangan film dalam bentuk prekuel trilogi film yang berjudul The Hobbit. Di kalangan remaja, film fantasi berjudul Twilight juga sukses dengan merilis empat filmnya.

\section{PEMBAHASAN}

\section{Komponen}

Film fantasi merupakan genre yang unik karena dapat dikombinasi dengan genre-genre yang lain tanpa terkecuali dan dapat dikembangkan secara luas tidak terbatas. Secara umum fantasi dalam film memungkinkan memuat hal-hal imajinasi fiktif yang tidak dapat diterima nalar. Penonton akan mendapatkan hal-hal baru yang belum pernah terpikirkan sebelumnya. Semakin tinggi daya imajinasi pembuat film, semakin kuat pula daya tarik sebuah film. Hal tersebut dikarenakan film fantasi memuat unsur-unsur dengan karakteristik yang berbeda dengan film-film yang lain. Ketika sebuah film fantasi memiliki satu unsur dalam pembuatan filmnya, maka sudah dikatakan sebagai film fantasi. Unsur atau komponen yang dilihat berasal dari unsur naratif dan sinematik pembuatan film yang di dalamnya memuat ide cerita, karakter, dan latar dalam sebuah film. Ketiga unsur tersebut adalah komponen pembentuk film fantasi yang bersifat fiktif dan imajinatif. Film fantasi tidak harus memenuhi ketentuan keseluruhan unsur bersifat fiktif dan imajinatif, namun jika sebuah film memiliki satu komponen bersifat fiktif dan imajinatif sudah dapat disebut film fantasi.

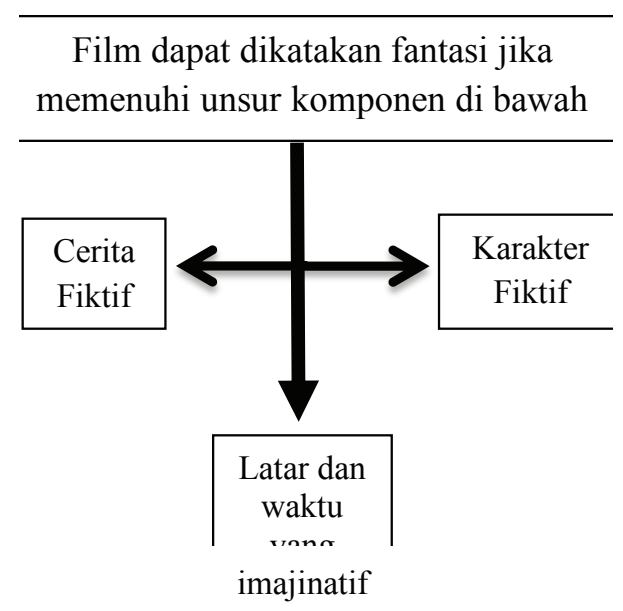

Bagan 1 Komponen-komponen pembentuk konsep fantasi 


\section{Cerita Fiktif}

Film fiksi seringkali menggunakan cerita rekaan di luar kejadian nyata serta memiliki konsep adegan yang telah dirancang sejak awal; terikat plot; struktur cerita film fiksi juga terikat hukum kausalitas (sebabakibat); pengklasifikasian tokoh-tokohnya juga memiliki karakter protagonis dan antagonis; adanya masalah dan konflik; penutupan; serta pola pengembangan cerita yang jelas. Film fiksi berada di tengah-tengah kutub: nyata dan abstrak, seringkali memiliki tendensi ke salah satu kutubnya, baik secara naratif maupun sinematik (Pratista, 2008). Ide ceritanya tidak berdasarkan kenyataan bersifat imajiner, yaitu karangan fiksi yang tidak masuk akal. Berbeda dengan karangan fiksi pada umumnya, fantasi dalam film memuat cerita-cerita di luar nalar dan kenyataan.

Tabel 1 Contoh film dengan cerita fiktif (tidak masuk akal)

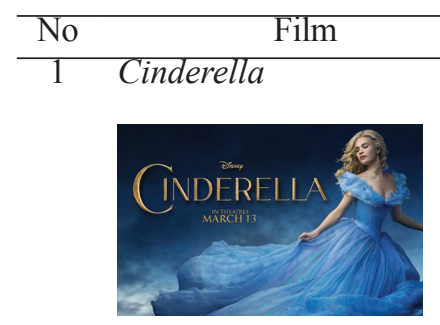

2

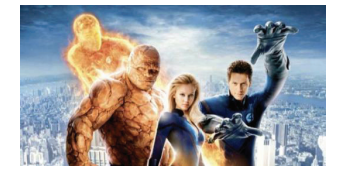

3 Spongebob Squarepants

4
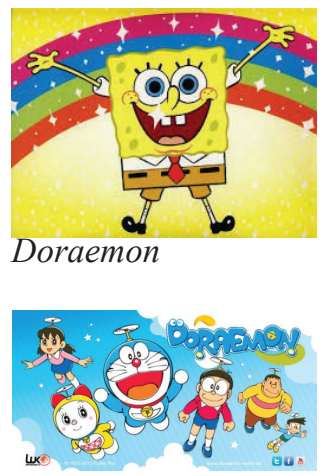

Kisah seorang gadis bernama Ella yang dicintai oleh pangeran namun ditentang oleh ibu tirinya karena mengingkan anak kandungnyalah yang nantinya akan dipersunting pangeran. Dengan pertolongan peri, Ella dapat menikah dengan pangeran tersebut dan hidup bahagia.

\section{Superhero}

Kisah manusia super yang mendapatkan kekuatan dari radiasi di planet lain. Keempat tokoh ini ingin dapat kembali seperti manusia normal namun dunia lebih membutuhkannya sebagai pelindung.

Fabel

Kisah yang menceritakan kehidupan di bawah laut, yaitu terdapat kepiting yang memiliki anak seekor ikan paus makan makanan yang lazim dimakan makhluk yang hidup di darat.

\section{Masa depan}

Kisah ini bercerita tentang seorang robot masa depan yang kembali ke masa lalu dengan membawa alat-alat ajaib untuk menolong seorang anak yang malas dan sulit berubah menjadi anak yang baik.

Imajinasi

Kisah ini merupakan cerita seorang penjaga museum yang kaget melihat semua benda di museum 'hidup' di malam hari dan 'mati' keesokan harinya. 
Ide cerita juga sering dikaitkan dengan cerita-cerita fiksi ilmiah, petualangan, supernatural, dan horor. Ide cerita merupakan kunci awal keberhasilan sebuah film. Tidak jarang penonton akan membaca sinopsis beberapa film sebelum memutuskan untuk melihat sebuah film. Oleh karena itu, ide film yang menarik dipadukan dengan desain poster dan trailer film yang kreatif akan menggiring penonton untuk memilih sebuah film. Dalam kasus film fantasi, pembuat film akan berlomba mengembangkan dan menghadirkan ide-ide yang belum terpikirkan sebelumnya sehingga penonton seakan-akan terbawa dalam dunia baru di luar kehidupan nyata. Berikut ini contohcontoh film fantasi dilihat dari penyusunan ide dan ceritanya yang sukses di pasaran dan dapat diterima baik oleh khalayak.

Ide cerita fantasi lebih spesifik bukan hanya fiksi semata yang tetaplah masuk akal dan mengandung kebenaran yang dapat mendramatisasikan hubungan-hubungan antarmanusia. Dalam fantasi, tokoh dalam cerita dapat berupa apa pun baik manusia maupun bukan, tidak dituntut masuk akal, memungkinkan semua bisa terjadi sesuai dengan kreativitas dan daya imajinasi kreatornya.

Komponen cerita fiktif yang menceritakan kejadian-kejadian fiktif di luar nalar membentuk sebuah film yang fantasi. Melalui cerita, penonton dapat melihat kehadiran fantasi pembuat cerita dan sutradara di dalamnya yang akan membuatnya sejenak hanyut merasakan kehidupan yang baru dalam dunia fantasi.

\section{Karakter Fiktif}

Karakter tokoh dalam film merupakan hasil imajinasi kreatornya. Biasanya karakter tersebut merupakan karakter nonmanusia seperti karakter binatang, makhluk luar angkasa, monster, robot, dan karakter nonfisik seperti hantu, arwah, dan hologram. Namun, tidak menutup kemungkinan karakter utamanya adalah seorang manusia pada umumnya. Untuk membentuk konsep fantasi ini karakter manusia (nonfiktif) tersebut akan berinteraksi dengan komponen yang lain. Film fantasi merupakan layar (screen) yang menjadi sekat tameng seseorang dari pertemuan dengan the real di sisi lain, secara mendasar fantasi (seperti yang disebut Freud: fundamental fantasy) yang menyediakan koordinasi dasar kemampuan seseorang untuk berhasrat (to desire) - tidak akan pernah disubjektifkan dan terepresi agar dapat berfungsi (Ali, 2010). 
Tabel 2 Karakter tokoh fantasi

Tokoh binatang
No.


Sebuah film masih dapat dikatakan fantasi walaupun karakter yang digunakan adalah manusia. Manusia normal bukan merupakan karaktif fiktif, melainkan manusia yang memiliki kekuatan di luar nalar manusia dan tidak dapat dibuktikan kebenarannya maka manusia tersebut dapat dikatakan karakter fiktif. Manusia yang menjadi tokoh dalam film fantasi berada dalam naungan cerita fiktif, latar yang tidak masuk akal, atau dapat pula berinteraksi dengan karakter lain yang fiktif sehingga film tersebut tetap dapat dikatakan fantasi. Setiap karakter manusia berinteraksi dengan komponen pembentuk konsep fantasi dalam film maka dapat digolongkan sebagai film fantasi. Manusia yang berperan dalam film fantasi sering kali harus berperan dengan sosok imajinatif sesuai tuntutan naskah. Oleh karena itu, kemampuan acting menjadi kunci utama. Karena bukan menjadi manusia atau dengan kata lain menjadi makhluk yang lain, seorang aktor harus berlatih mengingat-ingat segala emosi yang terpendam dari halaman-halaman sejarah yang telah silam untuk menolong aktingnya agar emosi bisa berkembang sesuai dengan situasi apa saja yang terdapat dalam sebuah cerita (Harymawan, 1988).

\section{Latar dan Waktu yang Imajinatif}

Dalam film dikenal dengan istilah mise en scene. Konsep mise en scene awalnya digunakan untuk pertunjukan teater sebelum akhirnya diadaptasi dalam film. Pada pertunjukan teater, konsep mise-en-cadre disebut dengan konsep mise-enscene, yaitu hubungan timbal balik dari orang-orang dalam aksinya atau dalam permainannya (Rohma, 2017). Selanjutnya, istilah mise-en-cadre lebih dikenal secara umum dalam istilah film sebagai mise-en-scene (Eisenstein, 1957). Salah satu konsep mise en scene di dalamnya memuat pembahasan mengenai latar dalam film.

Film fantasi mempunyai karakter film yang berlatar tempat dan waktu kejadian imajinatif mempunyai keunikan pada zaman atau dimensi yang tidak diketahui, dapat berupa masa lalu, masa sekarang, dan masa depan dengan perabadan yang dibentuk oleh kreatornya. Latar atau setting adalah pengaturan keseluruhan latar lengkap dengan segala propertinya (Bordwell \& Thompson, 1950). Dengan demikian, filmmaker dapat memadupadankan cerita dengan latar-latar yang unik sesuai dengan imajinasinya. Latar dan sebuah film menentukan suasana dalam film. Dalam membangun suasana sebuah tempat sengaja didesain secara unik agar emosi pemain dapat terbaca dengan baik oleh penonton. Contoh latar pembentuk konsep fantasi di antaranya alam mimpi, zaman purba, peradaban di masa depan, dan kehidupan di planet tertentu selain bumi. 
Tabel 3 Latar Tempat dan Waktu yang Imajinatif

\begin{tabular}{cc}
\hline No. & Film \\
\hline 1 & The Science of Sleep \\
& \\
& \\
&
\end{tabular}

$2 \quad$ Flinston Movie

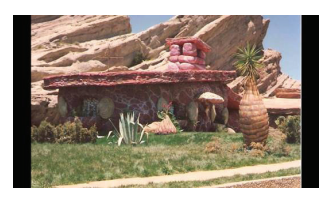

$3 \quad$ Jupiter Ascending

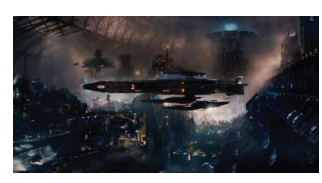

$4 \quad$ Avatar

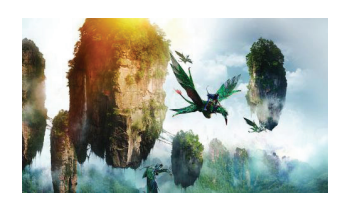

The Science of Sleep merupakan salah satu film fantasi yang mengambil lokasi berdasarkan alam mimpi tokoh utama Stéphane Miroux. Alam mimpi Stephane mengubah lokasi yang tidak mungkin menjadi mungkin, seperti danau di dalam kantor. Alam mimpi merupakan setting yang tidak terbatas dengan komponenkomponen baru dengan menghadirkan latar yang jauh berbeda dari kehidupan asli di dunia nyata.

Zaman purba

Flinston mengambil seting lokasi pada zaman prasejarah (zaman batu) ketika dinosaurus dan makhluk purba lainnya masih hidup. Film ini menggambarkan kemajuan manusia prasejarah yang modern. Setting film ini imajinatif karena bangunan rumah, gedung, kantor dibuat dari bebatuan dengan arstektur modern walau berada di setting film prasejarah.

\section{Peradaban masa depan}

Jupiter Ascending, film dengan latar belakang peradaban manusia masa depan, beserta ras sejenis manusia yang menghuni planet di luar bumi. Setting film ini diwarnai dengan berbagai bentuk kemajuan teknologi, seperti bangunan melayang dan kapal ruang angkasa. Film ini mengambil setting lokasi di Bumi dan Jupiter.

Kehidupan di planet tertentu

Film Avatar menyajikan setting yang berada di planet Pandora, sebuah ekosistem planet yang menakjubkan yang dihuni makluk sejenis manusia dengan sebutan Na'vi. Pesona alam Pandora, pulau terbang, gua yang penuh dengan gemerlap cahaya di luar kenyataan ini membentuk setting imajinatif.

\section{Alam peri}

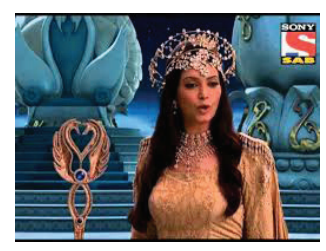

Baalveer mengambil setting di alam peri di atas langit bumi. Alam peri yang ada disesuaikan karakter peri yang menghuninya. Alam peri terdiri atas istana peri dan taman yang sangat indah. Setting alam peri yang lain dipenuhi propertiproperti berwarna gelap. 
Sama halnya dengan karakter, sebuah latar waktu dan tempat yang nyata pun juga dapat membetuk konsep fantasi. Hal tersebut dapat terjadi jika cerita yang terjadi di suatu tempat tersebut merupakan kisah yang tidak masuk akal dan tidak dapat terbukti kebenarannya. Namun, sebuah cerita yang di dalamnya memuat latar waktu yang imajinatif yang tidak diketahui asal usul peradabannya adalah komponen pembentuk konsep fantasi. Artinya latar yang imjinatif pasti membentuk konsep fantasi dan latar nyata juga dapat membentuk konsep fantasi apabila berinteraksi dengan komponen yang lainnya.

\section{Hubungan Antarkomponen}

Cerita Fiktif, Tokoh Fiktif, dan Latar Imajinatif

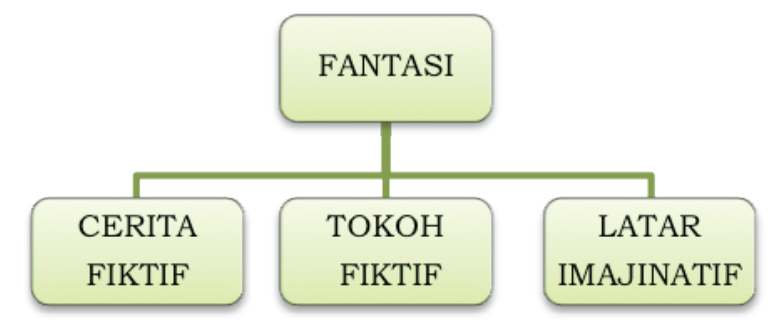

Bagan 2 Hubungan komponen cerita fiktif, tokoh fiktif, dan latar imajinatif

Sebuah film dikatakan fantasi memuat cerita fiktif karena karakter di dalamnya juga fiktif hidup dalam latar yang tidak diketahui. Hubungan komponen membentuk fantasi terlihat dalam gambar di atas yang mengisahkan seorang manusia berinteraksi dengan makhluk campuran hewan dan manusia hidup pada planet-planet yang ditopang oleh pilar-pilar jagat raya dan memiliki sistem tata surya sendiri. Hal tersebut tampak dalam frame terdapat dua pilar yang menyangga sebuah planet yang memiliki masing-masing sebuah matahari. Peradaban dalam frame tersebut sudah modern yang ditunjukkan oleh kostum yang dikenakan tokoh.

\section{Cerita Fiktif, Tokoh Fiktif, Latar Tidak Imajinatif}

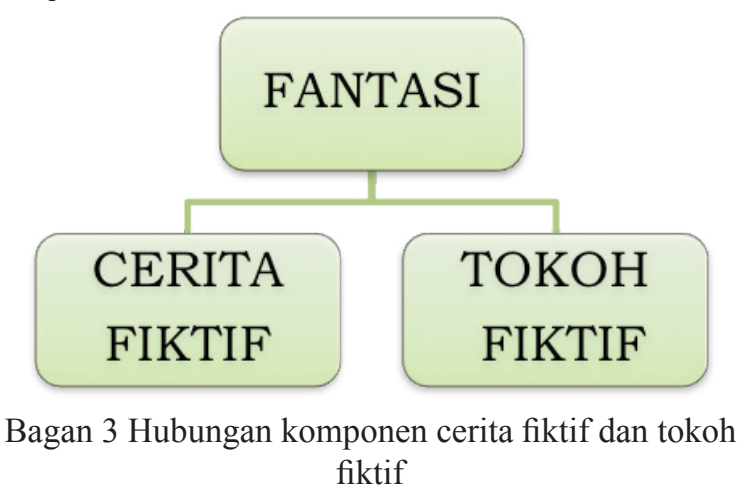

Sebuah film yang memuat cerita fiktif yang karakter di dalamnya juga fiktif hidup pada masa dan peristiwa tertentu dapat dikatakan fantasi. Hubungan komponen-komponen tersebut digambarkan dalam gambar di atas yang menceritakan makhluk berbadan manusia berkepala kelinci memiliki rumah layaknya tempat tinggal manusia pada umumnya. Selain itu, hubungan komponen tersebut juga dijumpai pada cerita Nyi Roro Kidul yang menemui Sultan Hamengkubuwono IX pada zaman perjuangan kemerdekaan Indonesia tahun 1945 di Pantai Parangkusuma. Hubungan komponen-komponen membentuk fantasi dalam film karena tetap memuat hal-hal di luar nalar manusia walaupun mengambil setting waktu dan tempat yang diketahui. 
Cerita Fiktif, Tokoh Tidak Fiktif, Latar Imajinatif

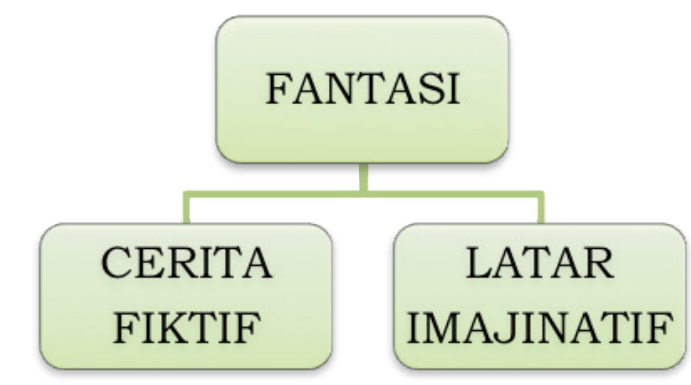

Bagan 4 Hubungan komponen cerita fiktif dan latar imajinatif

Sebuah film juga dapat dikatakan fantasi memuat cerita fiktif karena manusia hidup di latar yang tidak diketahui. Dalam gambar di atas, diceritakan bahwa seorang manusia dalam peradaban yang di dalamnya terdapat istana di atas langit dan penemuan canggih untuk mengembangkan energi planet, yaitu dapat menentukan besarnya gaya gravitasi sesuai kebutuhan. Hubungan komponen-komponen membentuk fantasi dalam film karena tetap memuat hal-hal di luar nalar manusia walaupun mengambil tokoh utama penggerak cerita adalah manusia (nonfiktif).

\section{Cerita Fiktif, Tokoh Tidak Fiktif, Latar Tidak Imajinatif}

Sebuah film yang memuat cerita fiktif ketika manusia hidup pada zaman tertentu. Misalnya dongeng mengenai Roro Jonggrang dan Bandung Bondowoso yang membangun Candi Prambanan. Walaupun tokoh utama dalam film tersebut adalah seorang manusia, dalam jalannya cerita tokoh tersebut berinteraksi dengan jin yang merupakan tokoh fiktif. Oleh karena itu, film tersebut tetap dikatakan fantasi walau tokoh utamanya tidak fiktif. Kasus ini memungkinkan hubungan antarkomponen tersebut dapat digolongkan sama seperti hubungan antarkomponen nomor dua, yaitu cerita fiktif, tokoh fiktif, dan latar tidak imajinatif.

\section{SIMPULAN}

Sebuah film yang bersifat fantasi pasti memiliki cerita yang fiktif. Penggunaan karakter fiktif dan latar imajinatif dapat digunakan keseluruhan secara bersamaan atau memilih salah satu komponen di antaranya. Artinya fantasi dalam film dapat menggunakan tiga komponen sekaligus atau memilih di antaranya disesuaikan dengan dunia baru yang ingin diciptakan. Perbedaan yang menonjol dalam konsep fantasi dibandingkan dengan ciri-ciri film fiksi bukan fantasi terdapat dalam cerita. Cerita yang digunakan dalam film fantasi adalah cerita yang tidak masuk akal dan tidak dapat dibuktikan kebenarannya pada masa lalu, sekarang, ataupun masa depan. Berikut merupakan tabel daya prediksi sebuah film dapat dikatakan fantasi.

Tabel Daya Prediksi Film Fantasi

\begin{tabular}{ccccc}
\hline No & $\begin{array}{c}\text { Cerita } \\
\text { Fiktif }\end{array}$ & $\begin{array}{c}\text { Karakter } \\
\text { Fiktif }\end{array}$ & $\begin{array}{c}\text { Latar } \\
\text { Imajinatif }\end{array}$ & Ket \\
\hline 1 & V & V & V & Fantasi \\
2 & V & V & - & Fantasi \\
\hline 3 & V & - & V & Fantasi \\
\hline
\end{tabular}

Dari tabel tersebut dapat disimpulkan bahwa setiap film fantasi mempunyai cerita yang tidak masuk akal, tidak dapat dibuktikan kebenarannya dan memiliki keterkaitan dengan komponen yang lain (karakter dan latar) untuk membentuk konsep fantasi. Komponenkomponen tersebut tidak dapat berdiri sendiri membentuk konsep fantasi, tetapi membutuhkan komponen yang lain untuk memperkuatnya. Konsep fantasi dapat dibentuk minimal dua komponen, yaitu cerita dan karakter, cerita dan latar, atau gabungan keseluruhan komponen tersebut. 


\section{KEPUSTAKAAN}

Ali, M. (2010). Psikologi Film, Membaca Film Lewat Psikoanalisis Lacan-Zizek (8 ed.). Jakarta: Fakultas Film dan Televisi Institut Kesenian Jakarta (FFTV IKJ).

Bordwell, D., \& Thompson, K. (1950). Film Art, An Introduction (8 ed.). New York: The McGraw-Hil.

Eisenstein, S. (1957). Film Form and The Film Sense. USA: Meredian Books.

Harymawan. (1988). Dramaturgi. Bandung: Remaja Rosda Karya.

Ismail, U. (1986). Mengupas Film. Jakarta: PT. Pustaka Sinar Harapan.

Luthfi, A. (2017). "Pendidikan Seni Film Dan Televisi Sebagai Penggerak Industri Ekonomi Kreatif'. REKAM: Jurnal Fotografi, Televisi, dan Animasi, 13(2), 99-106.

Pratista, H. (2008). Memahami Film. Yogyakarta: Homerian Ed 1.

Pratista, H. (2017). Memahami Film. Yogyakarta: Homerian Ed 2.

Rohma, N. N. (2017). "Estetika Formalis Film Pohon Penghujan Sutradara Andra Fembriarto". REKAM: Jurnal Fotografi, Televisi, dan Animasi, 13(1), 41-51.

Stokes, J. (2007). How To Do Media and Cultural Studies. Yogyakarta: Bentang.

Suwardi, H. (2006). Kritik Sosial dalam Film Komedi. Jakarta: FFTV-IKJ Press. 
